\title{
PENGARUH SENAM AEROBIK LOW IMPACT TERHADAP PERUBAHAN TEKANAN DARAH LANSIA HIPERTENSI
}

\author{
Ferawati \\ Program Studi S1 IImu Keperawatan \\ STIKes Insan Cendekia Husada Bojonegoro, ferawati622@gmail.com \\ Fatimatus Zahro \\ Nursing Center ICsada, fatimatuszahro349@gmail.com \\ Ulfa Hardianti \\ Nursing Center ICsada, hardiantiulfa@gmail.com
}

\begin{abstract}
ABSTRAK
Orang lanjut usia seringkali mengeluhkan masalah kesehatannya, salah satu keluhan adalah tekanan darah yang tinggi atau yang disebut Hipertensi. Hipertensi merupakan peningkatan tekanan darah $>140 / 90 \mathrm{mmHg}$. Hipertensi yang tidak terkontrol dapat mennyebabkan stroke dan gagal jantung. Aktivitas fisik pada lansia dapat membantu menurunkan hipertensi, salah satunya adalah senam. Pengobatan non-farmakologis dengan melakukan senam aerobik low impact merupakan salah satu alternatif pengobatan Hipertensi karena karena akan terjadi rileksasi dan dapat menyebabkan vasodilatasi pembuluh darah sehingga tekanan darah menurun. Tujuan penelitian ini adalah untuk mengetahui pengaruh senam aerobik low impact terhadap perubahan tekanan darah pada lansia dengan Hipertensi di Posyandu Lansia Desa Campurejo Kabupaten Bojonegoro.

Jenis penelitian adalah Pra eksperimental dengan rancangan penelitian one grup pretestposttest. Penelitian dilakukan di Posyandu Lansia Dusun Mlaten Desa Campurejo Kabupaten Bojonegoro. Subjek penelitian adalah lansia di posyandu lansia di Desa Campurejo yang mengalami hipertensi sebanyak 30 orang. Teknik sampling dengan purposive sampling. Instrument yang digunakan yaitu Spignomanometer dan stetoskop. Analisa data menggunakan uji t berpasangan (paired $t$ test).

Hasil Penelitian ini menunjukkan bahwa Tekanan darah sistole sebelum senam aerobik low impact rata-rata dengan tekanan darah $162,19 \mathrm{mmHg}$ dan diastole dengan rata-rata tekanan darah $92,09 \mathrm{mmHg}$. Tekanan darah sistole setelah senam aerobik low impact rata-rata dengan tekanan darah $155,91 \mathrm{mmHg}$ dan diastole dengan rata-rata tekanan darah 88,31 $\mathrm{mmHg}$. Hasil uji analisis dengan paired t test didapatkan nilai asymp. Sig (2-tailed) 0,000 ( $p$ $<0,05$ ) untuk tekanan darah sistolik dan 0,000 ( $p<0,05)$ untuk tekanan darah diastolik. Pemberian senam Aerobic Low Impact efektif terhadap penurunan tekanan darah lansia Hipertensi di posyandu lansia di Desa Campurejo Kabupaten Bojonegoro.
\end{abstract}

Kata Kunci : Hipertensi, Tekanan Darah, Senam aerobik low impact, Lansia

\section{ABSTRACT}

Elderly people often complain about their health problems, and one of the problems is over pressure in their blood called hypertension. Hypertension is a blood pressure $>140 / 90$ $\mathrm{mmHg}$ is often experienced by the elders. Uncontrolled hypertension can cause complications of stroke or heart failure. Physical activity in the elderly can help reduce hypertension, one of which is gymnastics. Non-pharmacology treatment by doing low impact aerobics gymnastics is one between so many alternative hypertension treatment, because there will be relaxation and its can caused vasodilation of the blood vessel that can cause drop in blood pressure. The 
purpose of this research was to determine the effect of low impact aerobic gymnastics on the changes of blood pressure in the elderly with hypertension in The elderly medical center in Campurejo village, Bojonegoro.

The study was a Pre experimental research design with one group pretest-posttest. The study was conducted in The elderly medical center Mlaten, Campurejo village, Bojonegoro. The research subject is the elders in the elderly medical center in Campurejo Village who experienced with hypertension as much as 30 people with purposive sampling. The research instrument were a measuring instruments spigmomamometer and stethoscope. The data were analyzed by using paired $t$-test.

The results before the implementation of low impact aerobic gymnastics of moderate intensity, the average systolic blood pressure was $162,19 \mathrm{mmHg}$ and the average diastolic was $92,09 \mathrm{mmHg}$ in blood pressure. After the implementation of low impact aerobic gymnastics of moderate intensity, the average systolic blood pressure was $155,91 \mathrm{mmHg}$ and the average diastolic was of $88,31 \mathrm{mmHg}$ in blood pressure. With analysis of test results paired t test get result asymp. Sig (2-tailed) 0,000 ( $p<0,05)$ for systolic blood pressure and for diastolic pressure. Giving aerobic low impact exercise effectively lowers blood pressure in people with hypertension.

Keywords : Hypertension, Blood Pressure, Low Impact Aerobic Gymnastic, Elderly

\section{PENDAHULUAN}

Hipertensi atau tekanan darah tinggi adalah tekanan darah persisten dimana tekanan sistoliknya diatas $140 \mathrm{mmHg}$ dan tekanan diastoliknya diatas $90 \mathrm{mmHg}$ (Palmer \& Williams, 2017). Tekanan darah tinggi (Hipertensi) merupakan masalah kesehatan yang tidak hanya dialami di Negara barat akan tetapi juga di Indonesia (Muhammadun, 2010). Ketidakteraturan untuk mengontrol tekanan darah dan juga meminum obat antihipertensi dapat menyebabkan kerusakan organ meliputi otak, karena hipertensi yang tidak terkontrol dapat meningkatkan resiko stroke kemudian kerusakan pada jantung (Mutaqqin, 2012).

Menurut World Health Organization (WHO) tahun 2015, dari populasi dunia kira-kira $42 \%$ orang dewasa umur diatas 25 tahun dengan jumlah 1,13 milliar orang didiagnosa terjangkit hipertensi. Diperkirakan juga setiap tahun ada 9,4 juta orang meninggal akibat hipertensi dan komplikasi. Angka ini terus meningkat tajam seiring perkembangan modernisasi di setiap negara (WHO, 2015). Menurut hasil Riset Kesehatan Dasar (RISKESDAS) tahun 2018 sebesar $25,8 \%$ warga diseluruh penduduk Indonesia terkena hipertensi. Penderita hipertensi pada tahun 2015 yang diperoleh di Provinsi Jawa Timur sebanyak 398.000 jiwa (10,8\%) (Profil Kesehatan, 2015). Di Kabupaten Bojonegoro tahun 2018 sebanyak 17.111 jiwa dari total warga bojonegoro menderita hipertensi dengan prosentase $7,01 \%$ dan menjadi 3 besar penyakit terbanyak diderita masyarakat Bojonegoro (radar bojonegoro.jawapos.com). Dari hasil studi pendahuluan penderita hipertensi di Prolanis Puskesmas Bojonegoro sebanyak 40 orang.

Kurangnya olahraga meningkatkan risiko menderita hipertensi karena kelebihan berat badan.Orang yang tidak aktif juga cenderung mempunyai frekuensi denyut jantung yang lebih tinggi sehingga otot jantungnya harus bekerja lebih keras pada setiap kontraksi, makin keras dan sering otot jantung harus memompa, makin besar tekanan yang dibebankan pada arteri (Palmer \& Williams, 2007).

Berbagai hal telah diketahui dapat mengontrol tekanan darah, salah satunya adalah latihan olahraga khususnya jenis 
aerobik. Senam aerobik dibagi menjadi dua yaitu high impact dan low impact. Senam yang cocok digunakan untuk orang yang menderita penyakit jantung maupun hipertensi yaitu jenis senam aerobik low impact karena merupakan senam yang gerakannya ringan dan bisa dilakukan siapa saja mulai dari usia anak-anak, dewasa bahkan lansia (Susanto, 2008).

Senam aerobik low impact merupakan suatu aktivitas fisik aerobik yang terutama bermanfaat untuk meningkatkan dan mempertahankan kesehatan dan daya tahan jantung, paru, peredaran darah, otot dan sendi.Senam ini dapat dilakukan dengan frekuensi latihan 35 kali dalam satu minggu dan dengan lama latihan 20-60 menit dalam satu kali latihan. Senam aerobik low impact dapat menyebabkan penurunan denyut jantung maka akan menurunkan cardiac output, yang pada akhirnya menyebabkan penurunan tekanan darah. Peningkatan efisiensi kerja jantung dicerminkan dengan penurunan tekanan sistolik, sedangkan penurunan tahanan perifer dicerminkan dengan penurunan tekanan diastolik (Harber \& Scoot, 2009).

Tujuan penelitian ini adalah untuk mengetahui pengaruh senam aerobik low impact terhadap tekanan darah pada penderita hipertensi Di Posyandu Lansia Desa Campurejo Kabupaten Bojonegoro. Penelitian ini diharapkan dapat membantu penderita hipertensi untuk memilih salah satu pendekatan non farmakologi yang efektif untuk menurunkan tekanan darah penderita hipertensi.

\section{METODE PENELITIAN}

Desain penelitian yang digunakan dalam penelitian ini adalah menggunakan metode penelitian pra-eksperimental dengan pendekatan one-group pre-post test design. Ciri tipe penelitian ini adalah mengungkapkan hubungan sebab akibat dengan cara melibatkan satu kelompok subjek. Kelompok subjek diobservasi sebelum dilakukan intervensi, kemudian diobservasi lagi setelah intervensi (Nursalam, 2013). .Kelompok eksperimen dilakukan pengukuran sebelum intervensi (pre-test), diberikan intervensi senam aerobik low impact selama 30 menitdan istirahat selama 10 menit kemudian dilakukan pengukuran (post-test). Senam aerobik low impact diberikan selama 3 hari berturut-turut.

Pengukuran tekanan darah menggunakan sphygmomanomet $\mathrm{ABN}$. Sampel dalam penelitian ini adalah 30 responden penderita hipertensi yang mengikuti posyandu lansia Dusun Mlaten Desa Campurejo Kabupaten Bojonegoro yang telah memenuhi kriteria inklusi.

Dalam penelitian ini teknik pengambilan sampel dengan non probability sampling dengan purposive sampling yaitu penetapan sampel dengan cara memilih sampel diantara populasi sesuai dengan yang dikehendaki peneliti (tujuan/masalah dalam penelitian), sehingga sampel tersebut dapat mewakili karakteristik populasi yang telah dikenal sebelumnya (Nursalam, 2008).

\section{HASIL PENELITIAN}

Berdasarkan hasil penelitian pada Bulan Agustus 2019 pada 30 responden dari 33 responden di Posyandu Lansia Dusun Mlaten Desa Campurejo. Karakteristik responden berdasarkan jenis kelamin dan usia dapat dilihat pada tabel berikut ini :

1. Distribusi frekuensi responden berdasarkan

Jenis kelamin

\begin{tabular}{llcc}
\hline No. & $\begin{array}{c}\text { Jenis } \\
\text { kelamin }\end{array}$ & $\mathbf{n}(\mathbf{3 0})$ & $\begin{array}{c}\text { Prosentase } \\
\mathbf{( \% )}\end{array}$ \\
\hline $\mathbf{1}$ & Laki-laki & 3 & 10 \\
\hline $\mathbf{2}$ & Perempuan & 27 & 90 \\
\hline & jumlah & 30 & 100 \\
\hline \multicolumn{2}{l}{ Sumber : Data Primer, Agustus } & 2019
\end{tabular}


Berdasarkan tabel diatas diketahui bahwa prosentase karakteristik responden yang menderita hipertensi berdasarkan jenis kelamin di Posyandu Lansia Dusun Mlaten Desa Campurejo lebih dari sebagian responden terjadi pada perempuan yakni sebanyak 27 $(90 \%)$ dari 30.

2. Distribusi Frekuensi Responden Berdasarkan Usia

\begin{tabular}{cccc}
\hline No & Usia & n (30) & $\begin{array}{c}\text { Prosentase } \\
\%\end{array}$ \\
\hline 1 & $36-45$ tahun & 3 & 10 \\
\hline 2 & $46-55$ tahun & 15 & 50 \\
\hline 3. & $56-65$ tahun & 8 & 26,7 \\
\hline 4. & $>65$ tahun & 4 & 13.3 \\
\hline & Jumlah & 30 & 100
\end{tabular}

Sumber: Data Primer, Agustus 2019

Berdasarkan tabel diatas diketahui bahwa prosentase karakteristik responden yang menderita hipertensi berdasarkan umur di Posyandu Lansia Dusun Mlaten Desa Campurejo sebagian responden berusia antara $46-$ 55 tahun (50\%) yaitu sebanyak 15 responden.

3. Disttribusi Klasifikasi Hipertensi Tekanan Darah Sistolik sebelum dan sesudah diberikan terapi senam aerobik Low Impact

\begin{tabular}{lcc}
\hline Pre & $\begin{array}{c}\text { Frekuensi } \\
(\mathrm{n})\end{array}$ & $\begin{array}{c}\text { Prosentase } \\
(\%)\end{array}$ \\
\hline Hipertensi 1 & 6 & 20 \\
Hipertensi 2 & 24 & 80 \\
\hline Post & & \\
\hline Hipertensi 1 & 17 & 56,7 \\
Hipertensi 2 & 13 & 43,3 \\
\hline Sumber : Data Primer, Agustus & 2019
\end{tabular}

Dari Tabel diatas diketahui bahwa klasifikasi hipertensi tekanan darah sistolik pre diketahui bahwa paling banyak pada kelompok hipertensi II yaitu sebanyak 24 orang $(80 \%)$, klasifikasi hipertensi tekanan darah sistolik post diketahui bahwa paling banyak kelompok Hipertensi I yaitu sebanyak 17 orang $(56,7 \%)$

4. Disttribusi Klasifikasi Hipertensi Tekanan Darah Diastol sebelum dan sesudah diberikan terapi senam aerobik Low Impact pada Penderita Hipertensi

\begin{tabular}{lcc}
\hline Pre & $\begin{array}{c}\text { Frekuensi } \\
(\mathrm{n})\end{array}$ & $\begin{array}{c}\text { Prosentase } \\
(\%)\end{array}$ \\
$\begin{array}{l}\text { Normal } \\
\text { Pre }\end{array}$ & 9 & 30 \\
Hipertensi & 2 & 6,7 \\
$\begin{array}{l}\text { Hipertensi } \\
1\end{array}$ & 6 & 20 \\
Hipertensi & 10 & 33,3 \\
2 & & \\
Hipertensi & 3 & 10 \\
3 & & \\
\hline Post & & \\
\hline $\begin{array}{l}\text { Normal } \\
\text { Pre }\end{array}$ & 10 & 33,3 \\
Hipertensi & 4 & 13,3 \\
Hipertensi & 10 & 33,3 \\
1 & & \\
Hipertensi & 6 & 20 \\
2 & & \\
Hipertensi & 0 & 0 \\
3 & & \\
\hline
\end{tabular}

Sumber : Data Primer, Agustus 2019

Dari Tabel 4.4 klasifikasi hipertensi tekanan darah diastolik pre diketahui bahwa paling banyak pada kelompok hipertensi II yaitu sebanyak 10 orang $(33,3 \%)$, klasifikasi hipertensi tekanan darah diastolik post diketahui bahwa paling banyak kelompok Hipertensi I yaitu sebanyak 10 orang $(33,3 \%)$ dan Normal sebanyak 10 orang (33,3\%)

5. Perbedaan Nilai tekanan darah Sistolik dan Diastolik sebelum dan sesudah diberikan terapi senam aerobik Low Impact pada Penderita Hipertensi di Posyandu Lansia Dusun Mlaten Desa Campurejo Bojonegoro. 


\begin{tabular}{lcc}
\hline \multicolumn{1}{c}{$\begin{array}{c}\text { Tekanan } \\
\text { darah }\end{array}$} & Mean & P Value \\
\hline Sistolik & & \\
Pre test & 162.19 & 0.000 \\
Post test & 155.91 & \\
\hline Diastolik & & \\
Pre test & 92.09 & 0.000 \\
Post test & 88.31 & \\
\hline \multicolumn{4}{l}{ Sumber : Data Primer, Agustus } & 2019
\end{tabular}

Dari tabel diatas dapat diketahui Ratarata tekanan darah sistolik pre test menunjukkan $162.19 \mathrm{mmHg}$ dan ratarata tekanan darah sistolik post test menurun menjadi $155.91 \mathrm{mmHg}$. Terdapat selisih 6,28 $\mathrm{mmHg}$. Sedangkan Rata-rata tekanan darah diastolik pre test menunjukkan $92,09 \mathrm{mmHg}$ dan ratarata tekanan darah diastolik post test menurun menjadi $88,31 \mathrm{mmHg}$. Terdapat selisih $3,78 \mathrm{mmHg}$. Dan secara uji statistik menunjukkan adanya perbedaan rata-rata tekanan darah pre test dan post test. Berdasarkan hasil tersebut diketahui angka signifikan $(0,00$ $<0,05)$ sehingga dapat diambil SIMPULAN Ho ditolak dan Ha diterima yang berarti ada pengaruh signifikan senam aerobik low impact terhadap perubahan tekanan darah diastole pada lansia.

\section{PEMBAHASAN}

Berdasarkan karakteristik responden peneliti menemukan bahwa yang mengalami hipertensi rata-rata berada pada rentang usia 46 sampai dengan 55 tahun. Pada umumnya tekanan darah akan meningkat dengan bertambahnya umur terutama setelah 40 tahun. Pada usia tersebut terjadi beberapa perubahan fisiologis sehingga resiko terkena hipertensi menjadi lebih besar, dimana arteri akan kehilangan elastisitas dan kelenturannya. Penelitian juga menunjukkan sebagian besar responden berjenis kelamin perempuan. Menurut Anggraini (2009) menyatakan bahwa perempuan akan mengalami peningkatan resiko tekanan darah tinggi setelah menopause yaitu usia diatas 45 tahun.

Hasil penelitian menunjukkan setelah senam Aerobik low impact terhadap perubahan tekanan darah pada lansia. Hal ini dapat dilihat dari penurunan tekanan darah sesudah senam aerobik low impact, rata-rata dari $162,19 / 92,09 \mathrm{mmHg}$ turun menjadi 155,91/88,31 mmHg.

Penurunan tekanan darah setelah senam aerobik menurun. Hal ini menurut Nafrialdi (2017), aktifitas fisik, terutama aerobik dapat meningkatkan aliran darah yang bersifat bergelombang yang mendorong produksi nitrit oksida (No) serta merangsang pembentukan pelepasan endothelial derive relaxing factor (EDRF), yang merelaksasi dan melebarkan pembuluh darah. Jika pembuluh darah mengecil maka tekanannya akan meningkat dan sebaliknya jika pembuluh darah melebar maka tekanan darah akan turun. Salah satu hasil latihan fisik yang teratur adalah pelebaran darah, sehingga tekanan darah yang tinggi akan menurun. Pengaturan lain yang akan mempengaruhi turunnya tekanan darah adalah terkendalinya pusat pengaturan darah di dalam tubuh dan hormonal yang biasa memacu tekanan darah semakin sedikit dikeluarkan atau dipakai. Semua faktor di atas memberi kontribusi turunnya tekanan darah.

Menurut Rismayanti (2009) salah satu faktor yang mempengaruhi hipertensi yaitu kurangnya berolahraga, latihan olahraga ini dapat menyebabkan dilatasi pembuluh pembuluh darah sehingga tekanan darah akan menurun. Orang yang melakukan latihan 2 kali dalam seminggu akan mengalami peningkatan daya tahan kardiorespirasi dan latihan olahraga secara teratur bisa menurunkan resiko penyakit jantung, karena olahraga aerobik bermanfaat untuk meningkatkan dan mempertahankan kesehatan daya tahan 
jantung, paru, peredaran darah, otot-otot, dan sendi-sendi, serta senam aerobic low impact mempunyai pengaruh besar terhadap tubuh, khususnya terhadap daya tahan paru dan jantung.

Berolahraga, seperti aktivitas aerobik, tekanan darah akan naik cukup banyak. Misalnya, selama melakukan latihan-latihan aerobic yang keras, tekanan darah sistolik dapat naik menjadi 150 - 200 $\mathrm{mmHg}$ dari tekanan sistolik ketika istirahat sebesar 110 - 120 mmHg. Sebaliknya, segera setelah latihan aerobik selesai, tekanan darah akan turun sampai di bawah normal dan berlangsung selama $30-120$ menit. Penurunan ini terjadi karena pembuluh darah mengalami pelebaran dan relaksasi. Penurunan ini akan nyata sekali pada penderita hipertensi. Olahraga aerobik yang dilakukan berulang-ulang menyebabkan penurunan tekanan darah, itulah sebabnya latihan olahraga secara teratur akan dapat menurunkan tekanan darah.

Senam aerobik low impact juga mempunyai kelebihan, namun menurut Gilang (2017) mempunyai kekurangan antara lain adalah aerobik low impact tidaklah bebas sama sekali dari kemungkinan mengalami cidera. Hal ini terjadi karena mereka melakukan gerakan tangan yang berlebihan, untuk memberikan kompensasi pada gerakan kaki yang hanya sedikit, dan dapat pula terjadi cedera pada bahu. Melakukan olahraga seperti senam aerobik low impact ini mampu mendorong jantung bekerja secara optimal, dimana olahraga untuk jantung mampu meningkatkan kebutuhan energi oleh sel, jaringan dan organ tubuh, dimana akibat peningkatan tersebutakan meningkatkan aktivitas pernafasan dan otot rangka, dari peningkatan aktivitas pernafasan akan meningkatkan aliran balik vena sehingga menyebabkan peningkatan volume sekuncup yang akan langsung meningkatkan curah jantung sehingga menyebabkan tekanan darah arteri meningkat sedang, setelah tekanan darah arteri meningkat akan terjadi fase istirahat terlebih dahulu, akibat dari fase ini mampu menurunkan aktivitas pernafasan otot rangka dan menyebabkan aktivitas saraf simpatis meningkat, setelah itu akan menyebabkan kecepatan jantung menurun, volume sekuncup menurun, vasodilatasi arteriol vena, karena penurunan ini mengakibatkan penurunan curah jantung dan penurunan resistensi perifertotal, sehingga terjadi penurunan tekanan darah (Sherwood, 2015).

Berdasarkan uji statistik, didapatkan $\mathrm{p}$ value tekanan darah sistolik yaitu 0,000 berarti $<0,005$, sedangkan tekanan darah diastolik mempunyai $p$-value 0,000 berarti p-value $<0,005$ maka HO ditolak, hal ini menunjukan bahwa terdapat pengaruh Senam Aerobic Low Impact Terhadap Penurunan Tekanan Darah Pada Penderita Hipertensi di Posyandu Lansia Dusun Mlaten Desa Campurejo Kabupaten Bojonegoro.

Penelitian ini didukung oleh penelitian yang dilakukan Lumempouw (2016) yang menyatakan bahwa senam prolanis aerobic low impact dapat menurunkan tekanan darah sistolik ratarata $10,00 \mathrm{mmHg}$ dan tekanan diastolik $6,00 \mathrm{mmHg}$, terdapat perbedaan bermakna antara tekanan darah diastolik awal dan akhir pada latihan $2 \mathrm{kali} /$ minggu $(p=0,002$ $<\alpha=0,001$.

Penelitian lain Lestari (2016) dengan judul Pengaruh Senam Prolanis Terhadap Penurunan Tekanan Darah Pada Penderita Hipertensi di Desa Perhentian Luas Wilayah Kerja UPTD Kesehatan. Perhentian Luas yang menyatakan bahwa terdapat pengaruh yang signifikan pada tekanan darah sistolik maupun diastolik sebelum dan sesudah diberikan senam PROLANIS pada penderita hipertensi di Desa Perhentian Luas dengan nilai $p$-value tekanan darah sistolik sebesar 0,000 dan tekanan darah diastolik sebesar 0,001. Hal ini berarti $\mathrm{H} 0$ ditolak dan $\mathrm{H} 1$ dapat diterima, 
artinya terdapat pengaruh senam PROLANIS terhadap penurunan tekanan darah pada penderita penyakit hipertensidi Desa Perhentian Luas Wilayah Kerja UPTD Kesehatan Perhentian Luas.

Senam aerobik low impact dapat meningkatkan jumlah darah yang dipompa setiap menitnya oleh jantung khususnya dari ventrikel kiri. Melalui peningkatan jumlah darah yang dipompa akan mengakibatkan jumlah oksigen yang beredar ke seluruh tubuh juga meningkat. Jumlah darah yang dipompa jantung bergantung kepada jumlah darah vena yang kembali ke jantung. Jantung akan memompa darah bila ada darah vena yang kembali ke jantung. Selama beraktivitas senam aerobik low impact, terjadi kontraksi otot, difusi oksigen karbonmonoksida di paru dan konstriksi vena, hal tersebut mengakibatkan peningkatan jumlah darah vena yang kembali ke jantung. Melakukan senam aerobik low impact akan memberikan keuntungan bagi tubuh terutama jantung dan paru. Otot jantung bertambah kuat, sehingga jantung dapat memompa darah lebih maksimal. Curah jantung meningkat sehingga dapat berdenyut lebih lambat. Disamping itu peningkatan suplai darah ke jantung semakin sempurna dengan berkembangnya pembuluh darah yang baru sehingga jantung mendapatkan lebih banyak zat makanan dan oksigen serta tidak mudah lelah.

Hasil penelitian ini serupa dengan penelitian Rismayanthi yang mendapatkan perbedaan bermakna tekanan darah diastolik pada penderita hipertensi stadium sedang sebelum dan sesudah melakukan senam aerobik. Rerata yang diperoleh tekanan darah diastolik sebelum perlakuan sebesar 103,733 dan rerata tekanan darah diastolik sesudah perlakuan sebesar 99,300. Dengan demikian dapat dikatakan, bahwa terjadi penurunan bermakna dari tekanan darah sesudah perlakuan senam aerobik low impact pada penderita hipertensi stadium sedang.

\section{KESIMPULAN}

Hasil penelitian menunjukkan bahwa karakteristik responden berdasarkan usia paling banyak berusia lansia yaitu ( $>46$ tahun) sebanyak 15 orang (50\%), dengan jenis kelamin perempuan sebanyak 27 orang (90\%). Hasil penelitian didapatkan adanya penurunan tekanan darah yang sangat signifikan pada kelompok eksperimen dengan diperoleh $p$ value 0,000 (sistole) dan $\mathrm{p}$ value 0,000 (diastole) $(p<0,05)$. Pengukuran diperoleh dari nilai mean tekanan darah pretest sistol pada kelompok eksperimen sebesar 162,19 $\mathrm{mmHg}$, pre-test diastol sebesar 92,09 $\mathrm{mmHg}$ dan post-test sistol sebesar 155,91 $\mathrm{mmHg}$, post-test diastol sebesar 88,31 $\mathrm{mmHg}$.

\section{SARAN}

1. Bagi Responden

Responden Disarankan untuk rutin mengikuti program kebugaran seperti senam aerobik low impact dan frekuensinya ditingkatkan lagi, misalnya seminggu 2 kali tidak hanya 1 kali.

2. Bagi peneliti Selanjutnya

Bagi peneliti selanjutnya, semoga penelitian ini dapat menjadi bahan referensi serta dapat dikembangkan dengan menambah variable lain seperti pengukuran tingkat saturasi oksigen yang berhubungan dengan senam aerobik low impact sehingga hasil lebih variatif.

3. Bagi Ketua Posyandu dan tim kesehatan setempat

Hendaknya dapat mengajak lansia untuk melakukan senam rutin minimal 1 minggu satu kali. Selain itu perlu dilakukan monitor tekanan darah bagi penderita Hipertensi. 
Ferawati, Fatimatus Zahro, Ulfa Hardianti, Pengaruh Senam Aerobik Low Impact Terhadap Perubahan Tekanan Darah Lansia Hipertensi.

\section{DAFTAR PUSTAKA}

Dalimartha. 2008. Care your self hipertensi. Penebar swadaya.

Departemen Kesehatan RI. (2013). Pedoman Teknis Penemuan dan Tatalaksana Penyakit Hipertensi. Jakarta: Direktorat Pengendalian Penyakit Tidak Menular.

Utomo,dkk. 2012. Latihan Senam Aerobik Untuk Menurunkan Berat Badan, Lemak, dan Kolesterol. Diakses dari journal.unnes.ac.id

Perdana, Revansia Missi. 2014. Efektivitas Senam Ergonomik Dengan Senam Aerobic Low Impact Terhadap Level Tekanan Darah Pada Lansia Hipertensi. Jurnal Universitas Muhammadiyah Surakarta.

Sari \& Sarifah. 2016. Senam Aerobik Low Impact Intensitas Sedang Terhadap Perubahan Tekanan Darah Pada Lansia. Jurnal Profesi, Volume 13, Nomor 2, Maret 2016.

Kementrian Kesehatan RI. (2015). Pedoman Pengendalian Hipertensi. Jakarta: Kemenkes RI 2015.

Lestyowati, Riris Eka. 2015. Motivasi Wanita Lansia Dini Terhadap Senam Aerobik Low Impact Di Tempat Arisan Rw 09 Pondok Benowo Indah. Jurnal Kesehatan Olahraga Tahun 2015.

Nafrialdi. 2017. Farmakologi dan Terapi. Edisi 5. Jakarta: Departemen Farmakologi dan Terapeutik. FKUI.

Putra, Prima Nurdiana. 2015. Efektivitas Senam Lansia dan Senam Aerobik Low Impact Terhadap Perubahan Tekanan Darah Pada Penderita Hipertensi di Baturaden. FIKES UMP, 2014.

Lestari, Eti. 2016. Pengaruh Senam Prolanis Terhadap penurunan
Tekanan Darah Pada Penderita Hipertensi Di Desa Perhentian Luas Wilayah Kerja Uptd Kesehatan Perhentian Luas. Skripsi STIKes TUANKU TAMBUSAI RIAU, 2016.

Muttaqin, Arif. 2012. Buku Ajar Asuhan Keperawatan Klien Dengan Gangguan Sistem Kardiovaskuler. Jakarta : Salemba Medika.

Nursalam. 2013. Metodologi penelitian ilmu keperawatan : pendekatan praktis edisi 3. Jakarta : Salmeba Medika.

Sugiyono. 2010. Metode Penelitian Pendekatan Kuantitatif, Kualitatif dan $R \& D$. Bandung : Alfabeta.

Wajan juni udjianti. 2013. Keperawatan kardiovaskular. Jakarta : Salemba Empat. 